\title{
BMI Perception: A potential cheap alternative to objectively measured BMI?
}

Frances Shiely ( $\square$ f.shiely@ucc.ie)

University College Cork https://orcid.org/0000-0003-0969-8321

Seán R Millar

University College Cork National University of Ireland

\section{Research article}

Keywords: Body Mass Index; Weight Status; BMI Perception; Misclassification

Posted Date: October 3rd, 2019

DOI: https://doi.org/10.21203/rs.2.15448/v1

License: (c) (1) This work is licensed under a Creative Commons Attribution 4.0 International License. Read Full License 


\section{Abstract}

\section{Background}

Accurately measuring BMI in large epidemiological studies is problematic as objective measurements are expensive, so subjective methodologies must usually suffice. A number of subjective methodologies have been shown to be inaccurate, resulting in misclassification to a lower BMI category and a subsequent underestimation of obesity prevalence. The purpose of this study is to explore a new subjective method of measuring BMI, BMI perception.

Methods

A cross-sectional analysis of the Mitchelstown Cohort Rescreen study, a random sample of 1354 men and women aged 51-77 years recruited from a single primary care centre. Data were collected using self-administered questionnaires. BMI perception was measured by asking "Do you think you are underweight, normal weight, overweight or obese?" Weight and height were also objectively measured.

Results

$79 \%$ of the cohort were overweight or obese: $86 \%$ of males, $69 \%$ of females, $\mathrm{P}<0.001$. The sensitivity for correct BMI perception for normal weight, overweight and obese was $77 \%, 61 \%$ and $11 \%$ respectively. $59 \%$ of overweight/obese participants underestimated their BMI. In multivariable analysis, gender, higher education levels, being told by a health professional to lose weight, and being on a diet were significantly associated with correct BMI perception. There was a linear trend relationship between increasing BMI levels and correct perception of BMl; participants in the highest BMI quartile had an approximate eight-fold increased odds of correctly perceiving their BMI when compared to participants within the lower overweight/obese quartiles $(\mathrm{OR}=7.72,95 \% \mathrm{Cl}: 4.59,12.98)$.

\section{Conclusions}

BMI perception as a subjective measurement of BMI has the potential to be an important measurement tool in large epidemiological studies. Clinicians need to be aware of disparities between BMI perception at the higher and lower BMI levels among overweight/obese patients and encourage preventative action for those at the lower levels to avoid weight gain and thus reduce their all-cause mortality risk.

\section{Background}

The conundrum of how to accurately measure body mass index (BMI) in large epidemiological samples has prompted much investigation, in many populations, over many years [1-9]. Despite this research, to date, the gold standard for accurate BMI classification is objectively measured weight and height. This is prohibitively expensive and not practical in large studies, due to the high costs involved. Usually self-report values of weight and height must suffice and although time and cost-efficient, have no guarantee of accuracy [7]. Both misclassification and misperception of weight status arising from BMI calculated from self-reported weight and height is common [8-13]. We know that self-reported weight is significantly lower than measured weight for both men and women $[2,5,8,12]$ and that self-reported height is significantly higher than measured height in adults $[2,5,8,9]$. This is problematic because it is an inaccurate measurement of BMI and leads to an overestimation between obesity and various health conditions $[12,14]$. It is also challenging because researchers postulate that correctly identifying oneself as being overweight is a prerequisite to successful weight management [15]. We know this is at least true in some situations because in our recent study of children, referred to a community weight management programme, we found that parental failure to recognise their child's overweight or obesity and denial of their child's weight status was a key factor underlying their lack of engagement in the programme [16].

Exploring new methods to obtain accurate BMI measurement are necessary. In recent years, the notion of self-perception of weight status has gained particular traction with much research focused on children and adolescents [17-20]. There are fewer studies of weight perception conducted on adults. A simple Google Scholar search of titles for "weight perception" or "weight misperception" in adults, since 2015, yielded just eight relevant articles [15, 21-27]. There are no studies extant on BMI perception. In this study, we hypothesised that given the increased awareness of overweight and obesity, asking adults to identify their own BMI category (termed BMI perception), by simply asking them "Do you think you are underweight, normal weight, overweight or obese?" would provide an 
accurate estimate of their BMI. This is the first study to test this hypothesis. A secondary outcome was to establish the factors influencing correct BMI perception. Finally, we investigated the impact different levels of overweight and obesity had on BMI perception.

\section{Methods}

\section{Study population and setting}

The Cork and Kerry Diabetes and Heart Disease Study (Phase II-Mitchelstown Cohort) was a single centre study (random sample) conducted between 2010 and 2011 in the Living Health Clinic, Mitchelstown, County Cork, Ireland. The Living Health Clinic serves a population of approximately 20,000 Caucasian-Europeans, with an urban/rural mix. Stratified sampling was employed to recruit equal numbers of men and women from all registered attending patients in the 46-73-year age group. In total, 3,807 potential participants were selected from the practice list. Following the exclusion of duplicates, deaths and participants incapable of consenting or attending appointment, 3,051 were invited to participate in the study and of these, 2,047 (49\% male) completed the self-administered questionnaire and physical examination components of the baseline assessment (response rate: 67\%). The doctor recorded gender during patient consultations. Details regarding the study design, sampling procedures and methods of data collection have been reported previously [28].

A rescreen of the Mitchelstown Cohort patients was conducted between 2016 and 2017 and this study is a secondary analysis of the Mitchelstown Cohort Rescreen dataset. Surviving baseline participants $(n=1,881)$ were invited to attend the re-screen. 166 were deemed unfit or too ill to take part by their doctor. 1,378 patients participated. Data on BMI perception and objectively measured BMI and were available for 1,364 participants. Due to low numbers of underweight participants, $B M I<18.5 \mathrm{~kg} / \mathrm{m}^{2}$, these participants were excluded. The final analysis consisted of 1,354 participants.

\section{Clinical procedures}

Data were collected by trained researchers with reference to a standard operating procedures manual. Height was measured with a portable Seca Leicester height/length stadiometer (Seca, Birmingham, UK) and weight was measured using a portable electronic Tanita WB-100MA weighing scale (Tanita Corp, IL, USA). The weighing scale was placed on a firm flat surface and was calibrated weekly. Body mass index (BMI) was calculated as weight in kilograms divided by height in meters squared $\left(\mathrm{kg} / \mathrm{m}^{2}\right)$.

Study participants attended the clinic in the morning after an overnight fast and blood samples were taken on arrival. Fasting glucose and glycated haemoglobin $\mathrm{A}_{1 \mathrm{c}}\left(\mathrm{HbA}_{1 \mathrm{c}}\right)$ levels were measured by Cork University Hospital Biochemistry Laboratory using standardised procedures and fresh samples. Glucose concentrations were determined using a glucose hexokinase assay (Olympus Life and Material Science Europa Ltd., Lismeehan, Co. Clare, Ireland) and $\mathrm{HbA}_{1 \mathrm{c}}$ levels were measured in the haematology laboratory on an automated high-pressure liquid chromatography instrument Tosoh G7 [Tosoh HLC-723 (G7), Tosoh Europe N.V, Tessenderlo, Belgium].

\section{Data collection}

A general health and lifestyle questionnaire was used to assess demographic variables, lifestyle behaviours and morbidity which included age, gender, education, living arrangement, self-rated health, smoking status, alcohol drinking habits, perceived diet quality, number of meals consumed in an average day, whether the participant had been told by a health professional to lose weight, whether they were on a diet to lose weight and the probability of a major depressive disorder and presence of type 2 diabetes. Physical activity levels were measured using the validated International Physical Activity Questionnaire (IPAQ) [29].

A validated Food Frequency Questionnaire (FFQ) consisting of 150 different food items was used for dietary assessment. The average medium serving of each food item consumed by participants over the last twelve months was converted into quantities using standard portion sizes. Food item quantity was expressed as $(\mathrm{gm} / \mathrm{d})$ and beverages as $(\mathrm{ml} / \mathrm{d})$. Based on the FFQ, the Dietary Approaches to Stop Hypertension (DASH) diet score was constructed. DASH is a dietary pattern rich in fruits, vegetables, whole grains and low-fat dairy foods and is limited in sugar-sweetened foods and beverages, red meat and added fats. This diet has been promoted by the National Heart, Lung and Blood Institute (part of the National Institutes of Health, a United States government 
organisation) to prevent and control hypertension. DASH diet scores ranged from 5-38. Lower scores represent poorer and higher scores represent better quality diet [30].

\section{Classification and scoring of variables}

We classified lifestyle behaviours using the same methodology as used previously in the SLÁN National Health and Lifestyle Survey [31] . Smoking status was defined as follows: (i) never smoked, i.e. having never smoked at least 100 cigarettes (5 packs) in their entire life; (ii) former smoker, i.e. having smoked 100 cigarettes in their entire life and do not smoke at present; and (iii) current smoker, i.e. smoking at present. A categorical variable was then created: 'Current' smoker, 'Former' smoker and 'Never' smoked.

Alcohol consumption was measured in units of alcohol consumed on a weekly basis and was categorised into the following levels: (i) non-drinker, i.e. $<1$ drink per week; (ii) moderate drinker, i.e. between 1 and 14 drinks per week; and (iii) heavy drinker, i.e. $>14$ drinks per week. Moderate drinker was defined on the basis of previous work from the European Prospective Investigation into Cancer and Nutrition (EPIC) in the United Kingdom (UK) by Khaw et al. [32]. For the current analysis, these were categorised as 'Heavy' drinker 'Moderate' drinker or 'Light' drinker.

Physical activity was categorised as low, moderate and high levels of activity using the IPAQ. We classified measured diet quality by dividing the DASH score into equal tertiles, with poorer diet quality defined as tertile 1 and higher diet quality defined as tertile 3 . Objectively measured weight status was categorised as BMI levels $18.5-24.9 \mathrm{~kg} / \mathrm{m}^{2}=$ 'Normal-weight', $25-29.9 \mathrm{~kg} / \mathrm{m}^{2}=$ 'Overweight' and $>30 \mathrm{~kg} / \mathrm{m}^{2}=$ 'Obese' .

Categories of education included 'some primary (not complete)', 'primary or equivalent', 'intermediate/group certificate or equivalent', 'leaving certificate or equivalent', 'diploma/certificate', 'primary university degree' and 'postgraduate/higher degree'. These were collapsed and recoded into a categorical variable: 'Primary only' and 'Secondary or diploma' and 'Bachelor or higher'. The validated Center for Epidemiologic Studies Depression Scale (CESD) was used to assess the probability of a participant having a major depressive disorder [33]. Type 2 diabetes was determined as a fasting glucose level $>7.0 \mathrm{mmol} / \mathrm{l}$ or a $\mathrm{HbA}_{1 \mathrm{c}}$ level $>6.5 \%(>48$ $\mathrm{mmol} / \mathrm{mol}$ ) [34] or by self-reported diagnosis.

\section{Outcome variable: BMI perception}

Study participants were asked the question "Do you think you are underweight, normal weight, overweight or obese?" Patterns of reporting bias were determined by cross-classifying the objectively measured BMI categories with the self-reported BMI perception categories. Participants who correctly classified their BMI were categorised as having a correct BMI Perception.

\section{Statistical analysis}

Descriptive characteristics were examined according to objectively measured BMI. Categorical features are presented as percentages and age is shown as a median and interquartile range. Logistic regression was used to determine associations between examined variables and BMI Perception. Independent univariate logistic regression models were fitted for each predictor and variables with a $\mathrm{P}$ value $<0.1$ were used to obtain a multivariable logistic regression model fit. Participants who were normal weight according to objectively measured BMI and those who overestimated their BMI perception were excluded $(n=295)$.

To observe whether objectively measured BMI levels influence BMI perception, participant true BMI values were divided into equal quartiles within the combined overweight and obese category and a variable was created with quartile 1 indicating lower overweight/obese levels and quartile 4 indicating higher values. A final logistic regression model was run to examine associations between higher BMI quartiles, i.e. the overweight/obese quartiles, and correct estimation of BMI perception adjusting for significant variables determined in multivariable analysis.

Data analysis was conducted using Stata SE Version 13 (Stata Corporation, College Station, TX, USA) for Windows. For all analyses, a $\mathrm{P}$ value (two-tailed) of less than.05 was considered to indicate statistical significance.

\section{Results}


Characteristics of the study population according to objectively measured BMI are presented in Table 1.

Insert Table 1 Here

Of the 1,354 participants' measured BMI, 290 (21\%) measured as normal weight, 627 (46\%) measured as overweight and 437 (32\%) measured as obese. Collectively, $79 \%$ of the cohort were either overweight or obese. A higher percentage of males were overweight or obese when compared to females ( $86 \%$ vs. $69 \%, \mathrm{P}<.001$ ). $77 \%$ of normal weight people correctly perceived their BMl group, $61 \%$ of overweight people were correct and just $11 \%$ of obese people. $59 \%$ percent of overweight and obese participants underestimated their BMI. Among overweight people, 237 (38\%) underestimated their weight, with 231 believing that they were normal weight. Among obese people, a majority 387 (89\%) underestimated their BMI, with 359 believing they were overweight and 28 indicating they perceived themselves to be normal weight. After excluding participants with a normal BMI and participants who overestimated their $\mathrm{BMI}, 45 \%$ of males and $55 \%$ of females correctly classified their BMI group.

\section{Logistic regression}

Table 2 focuses on overweight and obese participants only and presents results from univariate logistic regression analyses displaying associations between variables and correct BMI perception.

\section{Insert Table 2 here}

Females were twice as likely to correctly perceive their BMI compared to males ( $\mathrm{OR}=2.16,95 \% \mathrm{Cl}: 1.68,2.78)$. Other factors related to correct BMI perception were higher educational levels, having good self-rated health, not having diabetes, better diet quality as measured using DASH, not being told by a health professional to lose weight and being on a diet to lose weight. Obese participants were significantly less likely to correctly perceive their BMI compared to overweight participants.

In multivariable analysis (Table 3), gender, education and objectively measured obesity (defined by BMI) remained significantly associated with correct BMI perception. Females were more than twice as likely to correctly classify their BMI group (OR $=2.57,95 \%$ $\mathrm{Cl}: 1.83,3.61)$ than males, as were those with at least a Bachelor's degree $(\mathrm{OR}=2.03,95 \% \mathrm{Cl}: 1.11,3.70)$. In addition, participants who had been told by a health professional to lose weight were also more likely to correctly classify their BMI group $(\mathrm{OR}=1.88,95 \%$ $\mathrm{Cl}: 1.17,3.04)$, while participants who were on a diet to lose weight had three-fold increased odds of accurately classifying their BMI group (OR $=3.17,95 \% \mathrm{Cl}: 2.18,4.62)$. Those who measured as obese were significantly less likely to be correct $(\mathrm{OR}=0.03,95 \% \mathrm{Cl}$ : $0.02,0.06)$. The $c$ statistic for a model which included these variables was 0.84 ( $95 \mathrm{Cl}: 0.81,0.87)$, indicating that the model was good at separating cases from non-cases.

Insert Table 3 here

\section{BMI perception according to BMI levels}

Odds ratios for correct perception of BMI according to BMI levels are shown in Table 4.

Insert Table 4 here.

Amongst overweight and obese participants, there was a linear trend relationship between increasing BMI levels and correct classification of BMI, with participants who were more overweight or obese being more likely to perceive their BMI correctly. In a final model, participants in the highest BMI quartile had approximately an eight-fold increased odds of correctly perceiving their BMI when compared to participants within the lower overweight/obese quartile ( $\mathrm{OR}=7.72,95 \% \mathrm{Cl}: 4.59,12.98)$.

\section{Discussion}

We examined a new epidemiologic method of measuring BMI, BMI perception, which if effective would have the potential to change methodology and significantly reduce the costs of accurate BMI measurement in large epidemiological surveys. BMI perception has not previously been tested or reported in the literature. Misclassification bias was evident in all three BMI categories, but was most apparent in the obese category where a sensitivity of just $11.4 \%$ was recorded. BMI perception was influenced by gender, education, $\mathrm{BMI}$ group, being told to lose weight by a professional and being on a diet to lose weight. 
The high prevalence of overweight and obesity in our sample is concerning. We found that $79 \%$ of this population were either overweight or obese; $86.6 \%$ of males and $70.2 \%$ of females. This is an increase from our previous 2007 study of BMI misclassification whereby in the comparative age category, $75.6 \%$ were overweight or obese [35]. The most recent national comparator is the Healthy Ireland 2015 survey, a national survey of adults 15+ years [36].The available figures are categorised by gender and age so not directly comparable. The trend is similar however. In the 2015 survey, BMI for men and women respectively is: $45-54$ years: $76 \%$ and $62 \% ; 55-64$ years: $83 \%$ and $68 \% ; 65+$ years: $81 \%$ and $68 \%$. We can conclude that levels of obesity for this study concur with the national statistics for 2015 and have thus increased over time.

The sensitivity of the obese category in this study is extremely low (11.4\%), even when we compare it to our previous study of misclassification patterns between self-reported BMI (defined by self-reported weight and height) and objectively measured BMI (defined by measured weight and height), in which it was $53.4 \%$ in 2007 in a national study of adults over 18 years [8]. Although this study is more than 10 years old, and we are comparing different methodologies for BMI classification, we cannot conclude that this is a result of the differing methodologies as we had already seen a decline in the sensitivity of the obese category in the prior 10 years, from 1998 (79.5\%) to $2002(64 \%)$ to $53.4 \%$ in 2007 . It may be the case, and is in fact highly likely, that this decline is related to our inability to correctly perceive BMI/weight status. This is even more likely to be the case, supported by our current study, given the significant underestimation of BMI in both the overweight (37.8\%) and obese (88.6\%) categories. A decline in ability to perceive BMI and/or weight status is observed worldwide $[3,27,37]$ and Ireland appears to be no different. However, the trend has changed over time in Ireland. In our prior 2010 study [8], using 2007 data, the majority of misclassifications were in the overweight category, while in our current study, the majority of misclassifications were in the obese category. This is likely attributable to the overall rising rates of obesity in Ireland.

The linear trend relationship in the overweight/obese participants, between increasing BMI levels and correct BMI perception is a significant concern, particularly for clinicians. It is not unexpected that those with the highest BMI levels are more likely to correctly perceive their BMI because they are also more likely to have been told by a doctor to lose weight, are more likely to be on a diet to lose weight, and are thus more aware of their weight and BMI group. They are also the participants with the highest all-cause mortality risk as a result of metabolic sequelae including hyperlipidemia, hypertension, diabetes and cardiovascular disease [38]. However, the approximate eight-fold increased odds of being more likely to perceive their BMI correctly compared to the lower quartile, within the overweight/obese categories, is concerning. The question must be asked as to why this differential is so great? One possibility is that clinicians themselves underestimate their patients' BMI as they have been desensitised to obesity, given the rising levels of obesity in our population. It is likely they underestimate the BMI of patients at the lower end of the BMI overweight and obese spectrum, as the patients themselves do, and thus are less likely to recommend to these patients that they lose weight compared to those at the higher end of the BMI overweight/obese categories. Patients at these lower overweight/obese levels are at a substantial risk of becoming more overweight/obese leading to significant health risks, particularly if they are unaware of their BMI status, as seems to be the case here. The focus for clinicians should be on targeting this group to prevent further weight accumulation, by making them aware of their BMI status and recommending they lose weight to achieve normal BMI levels and thus reduce their all-cause mortality risk.

After excluding participants with a normal BMI and participants who overestimated their BMI, $45 \%$ of males and $55 \%$ of females correctly classified their BMI status. These figures are quite low, and are concerning for future generations given that a diagnosis or recognition of overweight or obesity is a first step towards acceptance and potential change [39]. Among obese people, a majority $387(89 \%)$ underestimated their $\mathrm{BMI}$, with 359 believing they were overweight and 28 indicating they perceived themselves to be normal BMI. We have previously hypothesised that in Ireland, there is a shift in the social norms of obesity $[8,9,20]$ and international evidence verifies this hypothesis [40]. Our closest neighbours, England, report similar findings and though it is a national sample of men and women $16+$ years, it is a useful comparator [37]. Overall, they report that $40 \%$ of men and $19 \%$ of women misperceive their weight, with men more likely than women to do so, and attribute it to the normalisation of overweight and obesity, which the author says is widespread in England.

In multivariable analysis, the factors associated with correct BMI perception are higher education level, gender, objectively measured $\mathrm{BMI}$, being told to lose weight or being on a diet. It is understandable that being told to lose weight or being on a diet is associated with correct perception, as it is likely that these people have been objectively measured recently. The association with higher education level, though concerning, is not new. We know that compared to less educated adults, more educated adults have lower average BMI and a lower risk of overweight and obesity in both the US [41] and Europe [42]. A recent publication attributes this more 
to selection than causation; children with lower BMI attain higher levels of education and higher educational attainment leads to lower BMI levels [43]. Therefore, this raises the important issue of tackling childhood obesity before it becomes an entrenched problem in adult life.

The gender disparity in BMI perception is clearly evident, with females more than twice as likely to perceive their BMI correctly compared to their male counterparts in multivariable analysis. We also know from this study that a higher proportion of males are overweight or obese. In a weight perception study in the US, this trend is also observed as well as a higher probability that women are more dissatisfied with their weight [44]. It could thus be argued that amongst females, there is a greater awareness of the ill effects of overweight and obesity, be it image-related or health-related, and thus they are more mindful of their BMI and monitor their weight, which in turn leads to a more accurate classification of their BMI. We know that weight and appearance satisfaction are associated with life satisfaction [45], thereby underlying the importance of accurate BMI perception to give realistic estimates of a 'healthy satisfying body weight'. The findings here, as well as in numerous other studies, highlights the necessity to consider men and women separately when targeting them for public health interventions to tackle obesity.

\section{Strengths and Limitations}

This is a large sample including objectively measured BMI derived from measured height and weight. The age range of the participants is limited to 51-77 years, therefore extrapolating findings to adults of other ages should be done with caution. However, the obesity levels are similar to the national statistics in 2015, thereby confirming a representative sample in this cohort. Missing data were not an issue in this study as the percentage of missing values in the variables of interest were extremely small, as evidenced by the large numbers in each table, therefore imputation was not necessary. Measurement bias is a consideration in this study but weight and height data in the Mitchelstown Cohort Study were measured by trained personnel using standardised equipment following a standard protocol thereby minimising any potential measurement biases. This is a cross-sectional study (albeit of a cohort), therefore causation cannot be inferred. We were unable to establish if BMI perception is superior to self-reported BMI (derived from self-reported weight and height) as self-reported weight and height were not collected, thereby limiting our comparisons. To truly examine the potential of BMI perception as a tool to measure BMI in large epidemiological studies, it would be most useful to compare it to self-reported BMI derived from self-reported weight and height, as well as objectively measured BMI, given that self-reported BMI based on weight and height is used most commonly. Future studies should also collect these data.

\section{Conclusions}

BMI perception is a potential cheap new method of measuring BMI in large epidemiological studies when objectively measuring it is not achieveable. As a first study focusing on BMI perception, it shows moderate sensitivity with objectively measured BMI for the normal and overweight categories, but poor sensitivity for the obese category. It is worth investigating the BMI perception method further and additional studies should include a broader age range. Furthermore, data should include all three measurements of BMI, self-reported BMI derived from self-reported height and weight, BMI perception and objectively measured BMI, to establish if BMI perception is at least superior to self-reported BMI, the method which is used most commonly in large epidemiological studies. The take home message for clinicians is to focus on those patients that appear to be 'normal weight' but clearly carry excess weight and urge them to be aware of their BMI and the significant risks to their health as a consequence of higher than normal BMI levels. These patients should be asked to lose weight and this should be monitored at each clinic visit. Public health policy makers should note the gender differences in this study and tailor their messages on BMI and obesity accordingly.

\section{Declarations}

\section{Acknowledgements}

Dr Janas Harrington and Professor Ivan Perry, Pls, Mitchelstown Cohort Study for allowing the use of the data.

\section{Funding}

This work was supported by a research grant from the Irish Health Research Board (reference: HRC/2007/13). The funders had no role in the study design, data collection and analysis, decision to publish or preparation of the manuscript. 
The authors declare no competing interests.

\section{Authors Contributions}

FS designed the study, drafted the background and discussion sections and contributed to the interpretation of the analysis. SM analysed the data, drafted the methods and the results sections. Both authors contributed to refining the paper for submission.

\section{Availability of Data and Materials}

The dataset used and analysed during the current study are available from the institution of the corresponding author on reasonable request.

\section{Ethics Approval and Consent to Participate}

Ethics committee approval conforming to the Declaration of Helsinki was obtained from the Clinical Research Ethics Committee of University College Cork. A letter signed by the contact GP in the clinic was sent out to all selected participants with a reply slip indicating acceptance or refusal. All participants gave signed informed consent, including permission to use their data for research purposes. The Mitchelstown Cohort Rescreen Study is GDPR compliant.

\section{Author's Information}

FS is a Senior Lecturer in Patient Focused Research at the HRB Clinical Research Facility and School of Public Health, University College Cork. She has a PhD in Epidemiology focused on methodology and throughout her career maintained a keen interest in BMI misclassification and the pursuit of alternative means of accurately measuring it. She is the co-PI for the HRB TMRN (Trials Methodology Research Network) and Director of TRAMS (Trials Research and Methodologies Group) at UCC. She is Programme Director for the online MSc Clinical Trials at UCC.

\section{References}

1.Bolton-Smith C, Woodward M, Tunstall-Pedoe H, Morrison C: Accuracy of the estimated prevalence of obesity from self-reported height and weight in an adult Scottish population. Journal of Epidemiology and Community Health 2000, 54:143-148.

2.Connor Gorber S, Tremblay M, Moher D, Gorber B: A comparison of direct vs. self-report measures for assessing height, weight and body mass index: a systematic review. Obesity Reviews 2007, 8:307-326.

3.Connor Gorber S, Tremblay MS: The bias in self-reported obesity from 1976 to 2005: a Canada-US comparison. Obesity 2010, 18(2):354-361.

4.Hayes AJ, Clarke PM, Lung TWC: Change in bias in self-reported body mass index in Australia between 1995 and 2008 and the evaluation of correction equations. Population Health Metrics 2011, 9(53).

5.Krul AJ, Daanen HAM, Choi J: Self-reported and measured weight, height and body mass index (BMI) in Italy, the Netherlands and North America. Eur J Public Health 2010, 21(4):414-419.

6.Lee DH, Shin A, Kim J, Yoo KY, Sung J: Validity of self-reported height and weight in a Korean Population. J Epidemiol 2011, 21(1):30-36.

7.Rothman KJ: BMI-related errors in the measurement of obesity. International Journal of Obesity 2008, 32:556-559.

8.Shiely F, Perry I, Lutomski J, Harrington J, Kelleher C, McGee H, Hayes K: Temporal trends in misclassification patterns of measured and self-report based body mass index categories - findings from three population surveys in Ireland. BMC Public Health 2010, 10(560):1-13.

9.Shiely F, Hayes K, Perry IJ, Kelleher CC: Height and Weight Bias: The Influence of Time. PLoS One 2013, 8(1):epub:1-8. 
10.Spencer EA, Appleby PN, Davey GK, Key TJ: Validity of self-reported height and weight in 4808 EPIC-Oxford participants. Public Health Nutrition 2002, 5(4):561-565.

11.Stommel M, Schoenborn CA: Accuracy and Usefulness of BMI Measures based on Self-Reported Weight and Height: Findings from the NHANES \& NHIS 2001-2006. BMC Public Health 2009, 9:421.

12.Robinson E, Oldham M: Weight status misperceptions among UK adults: the use of self-reported vs. measured BMI. BMC obesity 2016, 3(1):21 .

13.Stommel M, Osier N: Temporal changes in bias of body mass index scores based on self-reported height and weight. International journal of obesity 2013, 37(3):461.

14.Chiolero A, Peytremann-Bridevaux I, Paccaud F: Associations between obesity and health conditions may be oerestimated if selfreported body mass index is used. Obesity Reviews 2007, 8:373-374.

15.Robinson E, Hunger J, Daly M: Perceived weight status and risk of weight gain across life in US and UK adults. International journal of obesity 2015, 39(12):1721.

16.Kelleher E, McHugh SM, Harrington JM, Perry IJ, Shiely F: Understanding engagement in a family-focused, multicomponent, childhood weight management programme delivered in the community setting. Public health nutrition 2019:1-12.

17.Xu F, Greaney ML, Cohen SA, Riebe D, Greene GW: The Association between Adolescent's Weight Perception and Health Behaviors: Analysis of National Health and Nutrition Examination Survey Data, 2011-2014. Journal of obesity 2018, 2018.

18.Rietmeijer-Mentink M, Paulis WD, van Middelkoop M, Bindels PJE, van der Wouden JC: Difference between parental perception and actual weight status of children: a systematic review. Maternal and Child Nutrition 2013, 9:3-22.

19.Parkinson K, Drewett R, Jones A, Adamson A: Mothers' judgements about their child's weight: distinguishing facts from values. Child: Care, Health and Development 2013, 39(5):722-727.

20.Shiely F, Ng H, Berkery E, Murrin C, Kelleher C, Hayes K: The association between weight perception and BMI: report and measurement data from the growing up in Ireland cohort study of 9-year olds. International Journal of Obesity 2017, 41(1):46.

21.Park B, Cho HN, Choi E, Seo DH, Kim S, Park Y-R, Choi KS, Rhee Y: Self-perceptions of body weight status according to age-groups among Korean women: A nationwide population-based survey. PloS one 2019, 14(1):e0210486.

22.Sánchez CM, Dijkstra S, Visser M: Self-perception of body weight status in older Dutch adults. The journal of nutrition, health \& aging 2015, 19(6):612-618.

23.Hassan S, Ojo T, Galusha D, Martinez-Brockman JL, Adams OP, Maharaj R, Nazario C, Nunez M, Nunez-Smith M: Obesity and weight misperception among adults in the Eastern Caribbean Health Outcomes Research Network (ECHORN) Cohort Study. Obesity science \& practice 2018, 4(4):367-378.

24.Murillo R, Ali SA, Carmack C, Doss D: Activity and weight misperception among overweight and obese US adults. American journal of health behavior 2016, 40(1):12-20.

25.Sonneville K, Thurston I, Milliren C, Kamody R, Gooding H, Richmond T: Helpful or harmful? Prospective association between weight misperception and weight gain among overweight and obese adolescents and young adults. International journal of obesity 2016, 40(2):328.

26.Kim S, So W-Y: Secular trends in the prevalence of weight misperception among Korean adults, 2001-2013. Obesity research \& clinical practice 2018, 12(4):346-350.

27.Fang K, Li H, Ma A, Dong J, Xie J, Zhou Y, Qi K, Wei Y, Li G, Cao J: Weight underestimation for adults in Beijing and its association with chronic disease awareness and weight management. Lipids in health and disease 2018, 17(1):225. 
28. Kearney PM, Harrington JM, Mc Carthy VJ, Fitzgerald AP, Perry IJ: Cohort Profile: The Cork and Kerry Diabetes and Heart Disease Study. Int J Epidemiol 2013, 42(5):1253-1262.

29.Booth ML, Ainsworth BE, Pratt M, Ekelund U, Yngve A, Sallis JF, Oja P: International physical activity questionnaire: 12-country reliability and validity. Medicine \& Science in Sports \& Exercise 2003, 195(9131/03):3508-1381.

30. Harrington JM, Fitzgerald AP, Kearney PM, McCarthy VJ, Madden J, Browne G, Dolan E, Perry IJ: DASH diet score and distribution of blood pressure in middle-aged men and women. American Journal of Hypertension 2013, 26(11):1311-1320.

31. Harrington J, Perry I, Lutomski J, Morgan K, McGee H, Shelley E, Watson D, Barry M: SLÁN 2007: survey of lifestyle, attitudes and nutrition in Ireland. Dietary habits of the Irish population. Psychology Reports 2008:6.

32.Khaw K-T, Wareham N, Bingham S, Welch A, Luben R, Day N: Combined impact of health behaviours and mortality in men and women: the EPIC-Norfolk prospective population study. PLoS Medicine 2008, 5(1):e12.

33.Radloff LS: The CES-D scale: a self-report depression scale for research in the general population. Applied psychological measurement 1977, 1(3):385-401.

34.Association AD: Diagnosis and classification of diabetes mellitus. Diabetes Care 2013, 36(Suppl 1):S67-S74.

35.Morgan K, McGee H, Watson D, Perry I, Barry M, Shelley E, Harrington J, Molcho M, Layte R, Tully N et al: SLÁN 2007: Survey of Lifestyle, Attitudes and Nutrition in Ireland. Main Report. In. Dublin: Department of Health and Children; 2008.

36.Government of Ireland: Healthy Ireland Survey. Summary of Findings Dublin, Healthy Ireland 2015.

37.Muttarak R: Normalization of plus size and the danger of unseen overweight and obesity in England. Obesity 2018, 26(7):11251129.

38.Moussa OM, Erridge S, Chidambaram S, Ziprin P, Darzi A, Purkayastha S: Mortality of the severely obese: a population study. Annals of Surgery 2019, 269(6):1087-1091.

39.Easton JF, Stephens CR, Sicilia HR: An Analysis of Real, Self-Perceived, and Desired BMI: Is There a Need for Regular Screening to Correct Misperceptions and Motivate Weight Reduction? Frontiers in Public Health 2017, 5(12).

40.Robinson E, Christiansen P: The changing face of obesity: exposure to and acceptance of obesity. Obesity 2014, 22(5):13801386.

41.Ogden CL, Fakhouri TH, Carroll MD, Hales CM, Fryar CD, Li X, Freedman DS: Prevalence of obesity among adults, by household income and education-United States, 2011-2014. MMWR Morbidity and mortality weekly report 2017, 66(50):1369.

42.Gallus S, Lugo A, Murisic B, Bosetti C, Boffetta P, La Vecchia C: Overweight and obesity in 16 European countries. European Journal of Nutrition 2015, 54(5):679-689.

43.Benson R, von Hippel PT, Lynch JL: Does more education cause lower BMI, or do lower-BMI individuals become more educated? Evidence from the National Longitudinal Survey of Youth 1979. Social Science \& Medicine 2018, 211:370-377.

44.Tsai SA, Lv N, Xiao L, Ma J: Gender differences in weight-related attitudes and behaviors among overweight and obese adults in the United States. American Journal of Men's Health 2016, 10(5):389-398.

45.Frederick DA, Sandhu G, Morse PJ, Swami V: Correlates of appearance and weight satisfaction in a US national sample: Personality, attachment style, television viewing, self-esteem, and life satisfaction. Body Image 2016, 17:191-203.

\section{Tables}

Table 1. Characteristics of the study population - all subjects and stratified by objectively measured BMI ${ }^{1}$. 


\begin{tabular}{|c|c|c|c|c|}
\hline Variable & $\begin{array}{l}\text { Total } \\
\mathrm{n}=1354\end{array}$ & $\begin{array}{l}\text { Normal weight } \\
n=290\end{array}$ & $\begin{array}{l}\text { Overweight } \\
\mathrm{n}=627\end{array}$ & $\begin{array}{l}\text { Obese } \\
n=437\end{array}$ \\
\hline Age in years. Mean (SD) & $65(61,69)$ & $64(60,69)$ & $65(61,70)$ & $66(61,69)$ \\
\hline \multicolumn{5}{|l|}{ Gender } \\
\hline \begin{tabular}{l|l} 
Male \\
\end{tabular} & $689(50.9)$ & $92(31.7)$ & $345(55.0)$ & $252(57.7)$ \\
\hline \begin{tabular}{l|l} 
Female \\
\end{tabular} & $665(49.1)$ & $198(68.3)$ & $282(45.0)$ & $185(42.3)$ \\
\hline \multicolumn{5}{|l|}{ BMI Perception } \\
\hline Underweight & $33(2.4)$ & $27(9.3)$ & $6(1.0)$ & $0(0)$ \\
\hline Normal weight & $483(35.7)$ & $224(77.2)$ & $231(36.8)$ & $28(6.4)$ \\
\hline Overweight & $783(57.8)$ & $29(13.4)$ & $385(61.4)$ & $359(82.2)$ \\
\hline \begin{tabular}{l|l} 
Obese \\
\end{tabular} & $55(4.1)$ & $0(0)$ & $5(0.8)$ & $50(11.4)$ \\
\hline \multicolumn{5}{|l|}{ Education } \\
\hline \begin{tabular}{l|l} 
Primary only \\
\end{tabular} & $311(24.9)$ & $60(22.4)$ & $131(22.5)$ & $120(30.0)$ \\
\hline Secondary or diploma & $810(64.7)$ & $172(64.2)$ & $383(65.7)$ & $255(63.8)$ \\
\hline \begin{tabular}{|l|l|} 
& Bachelor or higher \\
\end{tabular} & $130(10.4)$ & $36(13.4)$ & $69(11.8)$ & $25(6.2)$ \\
\hline \multicolumn{5}{|l|}{ Married or cohabiting } \\
\hline \begin{tabular}{l|l} 
Yes \\
\end{tabular} & $1061(78.5)$ & $242(83.4)$ & $494(78.9)$ & $325(74.5)$ \\
\hline \multicolumn{5}{|l|}{ Self-rated health } \\
\hline Good & $1151(85.0)$ & $256(88.3)$ & $555(88.5)$ & $340(77.8)$ \\
\hline \multicolumn{5}{|l|}{ Probable major depressive disorder } \\
\hline Yes & $89(6.8)$ & $16(5.7)$ & $35(5.8)$ & $38(9.0)$ \\
\hline \multicolumn{5}{|l|}{ Type 2 diabetes } \\
\hline Yes & $138(10.2)$ & $16(5.5)$ & $41(6.5)$ & $81(18.5)$ \\
\hline \multicolumn{5}{|l|}{ Physical activity level } \\
\hline Low & $960(70.9)$ & $204(70.3)$ & $423(67.5)$ & $333(76.2)$ \\
\hline Moderate & $352(26.0)$ & $74(25.5)$ & $181(28.9)$ & $97(22.2)$ \\
\hline \begin{tabular}{l|l|} 
High \\
\end{tabular} & $42(3.1)$ & $12(4.1)$ & $23(3.7)$ & $7(1.6)$ \\
\hline \multicolumn{5}{|l|}{ Smoking status } \\
\hline | Current & $120(8.9)$ & $37(12.8)$ & $49(7.8)$ & $34(7.8)$ \\
\hline \begin{tabular}{|l|} 
Former \\
\end{tabular} & $517(38.2)$ & $76(26.2)$ & $244(38.9)$ & $197(45.1)$ \\
\hline \begin{tabular}{l|l} 
Never \\
\end{tabular} & $717(53.0)$ & $177(61.0)$ & $334(53.3)$ & $206(47.1)$ \\
\hline \multicolumn{5}{|l|}{ Alcohol use } \\
\hline \begin{tabular}{|l|l} 
& Heavy \\
\end{tabular} & $99(10.3)$ & $11(5.3)$ & $50(10.8)$ & $38(13.0)$ \\
\hline Moderate & $552(57.4)$ & $118(56.7)$ & $283(61.4)$ & $151(51.5)$ \\
\hline \begin{tabular}{l|l} 
Light \\
\end{tabular} & $311(32.3)$ & $79(38.0)$ & $128(27.8)$ & $104(35.5)$ \\
\hline \multicolumn{5}{|l|}{ Measured diet quality } \\
\hline Poor & $483(36.3)$ & $93(32.9)$ & $204(32.9)$ & $186(43.4)$ \\
\hline Moderate & $476(35.7)$ & $98(34.6)$ & $236(38.1)$ & $142(33.1)$ \\
\hline \begin{tabular}{l|l} 
Good \\
\end{tabular} & $373(28.0)$ & $92(32.5)$ & $180(29.0)$ & $101(23.5)$ \\
\hline \multicolumn{5}{|l|}{ Perceived diet quality } \\
\hline \begin{tabular}{|l|l} 
Poor \\
\end{tabular} & $158(15.5)$ & $17(8.3)$ & $41(9.1)$ & $100(27.5)$ \\
\hline \begin{tabular}{|l|} 
Average \\
\end{tabular} & $761(74.5)$ & $164(79.6)$ & $357(78.8)$ & $240(66.1)$ \\
\hline \begin{tabular}{l|l|} 
& Healthy \\
\end{tabular} & $103(10.1)$ & $25(12.1)$ & $55(12.1)$ & $23(6.3)$ \\
\hline \multicolumn{5}{|l|}{ Number of complete meals per day } \\
\hline One meal & $45(3.3)$ & $9(3.1)$ & $20(3.2)$ & $16(3.7)$ \\
\hline Two meals & $207(15.3)$ & $31(10.7)$ & $98(15.7)$ & $78(17.8)$ \\
\hline \begin{tabular}{|l|l|} 
Three meals \\
\end{tabular} & $1100(81.4)$ & $250(86.2)$ & $507(81.1)$ & $343(78.5)$ \\
\hline \multicolumn{5}{|l|}{ Told by health professional to lose weight } \\
\hline Yes & $252(18.6)$ & $4(1.4)$ & $62(9.9)$ & $186(42.6)$ \\
\hline \multicolumn{5}{|l|}{ On diet to lose weight } \\
\hline Yes & $534(39.4)$ & $32(11.0)$ & $233(37.2)$ & $269(61.6)$ \\
\hline
\end{tabular}

Age is shown as a median (interquartile range). Numbers and \% (in brackets) for categorical variables will vary in different analyses as some variables have missing values.

${ }^{1}$ Normal weight $=$ BMI: $18.5-24.9 \mathrm{~kg} / \mathrm{m}^{2}$; Overweight $=$ BMI $: 25.0-29.9 \mathrm{~kg} / \mathrm{m}^{2} ;$ Obese $=\mathrm{BMI}: \geq 30 \mathrm{~kg} / \mathrm{m}^{2}$.

Table 2. Unadjusted odds ratios ${ }^{1}$ for factors associated with correct estimation of BMI among overweight and obese subjects. 


\begin{tabular}{|c|c|c|c|c|c|c|}
\hline Variable & & $\begin{array}{l}\text { Correct estimation of BMI status } \\
n=435\end{array}$ & $\begin{array}{l}\text { Underestimation of BMI } \\
\text { status } \\
n=624\end{array}$ & OR $(95 \%$ CI $)$ & & lue \\
\hline Age in yea & & $65(60,69)$ & $66(61,70)$ & $\begin{array}{ll}0.99 & (0.96, \\
1.01) & \end{array}$ & & .184 \\
\hline Gender & & & & & & \\
\hline & Male & $196(45.1)$ & $399(63.9)$ & 1 (Referen & ce) & \\
\hline & Female & $239(54.9)$ & $225(36.1)$ & $2.16(1.68$ & 2.78) & $<.001$ \\
\hline Objectivel & y measured weight stat & & & & & \\
\hline & Overweight & $385(88.5)$ & $237(38.0)$ & 1 & & \\
\hline & Obese & $50(11.5)$ & $387(62.0)$ & $0.08(0.06$ & $0.11)$ & $<.001$ \\
\hline Education & & & & & & \\
\hline & \begin{tabular}{|l|} 
Primary only \\
\end{tabular} & $80(19.8)$ & $170(29.6)$ & 1 (Referen & ce) & \\
\hline & Secondary or diploma & $271(67.1)$ & $365(63.5)$ & $1.58(1.16$ & $2.15)$ & .004 \\
\hline & Bachelor or higher & $53(13.1)$ & $40(7.0)$ & $2.82(1.73$ & 4.59) & $<.001$ \\
\hline Married o & r cohabiting & & & & & \\
\hline & No & $92(21.2)$ & $149(23.9)$ & 1 (Referen & ce) & \\
\hline & \begin{tabular}{|l|} 
Yes \\
\end{tabular} & $342(78.8)$ & $474(76.1)$ & $1.17(0.87$ & 1.57) & .300 \\
\hline Self-rated & health & & & & & \\
\hline & Poor & $49(11.3)$ & $118(18.9)$ & 1 (Referen & ce) & \\
\hline & Good & $386(88.7)$ & $506(81.1)$ & $1.84(1.28$ & 2.63) & .001 \\
\hline $\begin{array}{l}\text { Probable } \\
\text { disorder }\end{array}$ & major depressive & & & & & \\
\hline & No & $392(92.7)$ & $559(93.0)$ & 1 (Referen & ce) & \\
\hline & Yes & $31(7.3)$ & $42(7.0)$ & $1.05(0.65$ & 1.70) & .835 \\
\hline Type 2 dia & betes & & & & & \\
\hline & No & $400(92.0)$ & $537(86.1)$ & 1 (Referen & ce) & \\
\hline & \begin{tabular}{|l|} 
Yes \\
\end{tabular} & $35(8.0)$ & $87(13.9)$ & $0.54(0.36$ & $0.82)$ & .003 \\
\hline Physical a & ctivity level & & & & & \\
\hline & \begin{tabular}{|l|} 
Low \\
\end{tabular} & $303(69.7$ & $449(72.0)$ & 1 (Referen & ce) & \\
\hline & Moderate & $121(27.8)$ & $156(25.0)$ & $1.15(0.87$ & $1.52)$ & 327 \\
\hline & \begin{tabular}{|l|} 
High \\
\end{tabular} & $11(2.5)$ & $19(3.0)$ & $0.86(0.40$ & 1.83) & .691 \\
\hline Smoking s & tatus & & & & & \\
\hline & Current & $33(7.6)$ & $50(8.0)$ & 1 (Referen & & \\
\hline & Former & $175(40.2)$ & $264(42.3)$ & $1.00(0.62$ & 1.62) & .986 \\
\hline & \begin{tabular}{|l|} 
Never \\
\end{tabular} & $227(52.2)$ & $310(49.7)$ & $1.11(0.69$ & 1.78) & .666 \\
\hline Alcohol us & & & & & & \\
\hline & \begin{tabular}{|l|} 
Heavy \\
\end{tabular} & $34(10.5)$ & $54(12.7)$ & 1 (Referen & ce) & \\
\hline & Moderate & $196(60.3)$ & $236(55.5)$ & $1.32(0.83$ & $2.11)$ & .665 \\
\hline & \begin{tabular}{|l|} 
Light \\
\end{tabular} & $95(29.2)$ & $135(31.8)$ & $1.12(0.68$ & 1.85) & .247 \\
\hline Measured & diet quality & & & & & \\
\hline & \begin{tabular}{|l|l|} 
Poor \\
\end{tabular} & $128(29.8)$ & $260(42.3)$ & 1 (Referen & & \\
\hline & Moderate & $163(38.0)$ & $213(34.6)$ & $1.55(1.16$ & 2.09) & .003 \\
\hline & \begin{tabular}{|l|} 
Good \\
\end{tabular} & $138(32.2)$ & $142(23.1)$ & $1.97(1.44$ & $2.71)$ & $<.001$ \\
\hline Perceived & diet quality & & & & & \\
\hline & \begin{tabular}{|l|l|} 
Poor \\
\end{tabular} & $53(15.7)$ & $87(18.4)$ & 1 (Referen & & \\
\hline & Average & $250(74.0)$ & $345(72.8)$ & $1.19(0.82$ & 1.74) & .369 \\
\hline & Healthy & $35(10.4)$ & $42(8.9)$ & $1.37(0.78$ & $2.40)$ & .276 \\
\hline $\begin{array}{l}\text { Number } \\
\text { day }\end{array}$ & of complete meals per & & & & & \\
\hline & One meal & $16(3.7)$ & $20(3.2)$ & 1 (Referen & ce) & \\
\hline & Two meals & $61(14.1)$ & $115(18.5)$ & $0.66(0.32$ & 1.37) & .268 \\
\hline & Three meals & $357(82.3)$ & $488(78.3)$ & $0.91(0.47$ & 1.79) & .794 \\
\hline $\begin{array}{l}\text { Told by } \\
\text { lose weigh }\end{array}$ & $\begin{array}{l}\text { health professional tc } \\
\text { th }\end{array}$ & & & & & \\
\hline & No & $364(83.7)$ & $449(72.0)$ & 1 (Referen & $\mathrm{ce})$ & \\
\hline & \begin{tabular}{|l|} 
Yes \\
\end{tabular} & $71(16.3)$ & $175(28.0)$ & $0.50(0.37$ & $0.68)$ & $<.001$ \\
\hline On diet to & lose weight & & & & & \\
\hline & \begin{tabular}{|l|l|l|l} 
No \\
\end{tabular} & $210(48.3)$ & 349 (55.9) & 1 (Referen & ce) & \\
\hline & Yes & $225(51.7)$ & $275(44.1)$ & $1.36(1.06$ & 1.74) & .014 \\
\hline
\end{tabular}

Age is shown as a median (interquartile range). Numbers and \% (in brackets) for categorical variables will vary in different analyses as some variables have missing values.

${ }^{1}$ Odds ratios (OR) and $95 \%$ confidence intervals (CI) for correct versus underestimation of BMI.

${ }^{2}$ Overweight = BMI: $25.0-29.9 \mathrm{~kg} / \mathrm{m}^{2}$; Obese $=$ BMI: $\geq 30 \mathrm{~kg} / \mathrm{m}^{2}$.

Significant $\mathrm{P}$ values $(<.05)$ highlighted.

Table 3. Adjusted odds ratios ${ }^{1}$ for factors associated with correct BMI perception among overweight and obese subjects. 


\begin{tabular}{|c|c|c|c|}
\hline Variable & OR (95\% CI) & P value & Wald \\
\hline \multicolumn{4}{|l|}{ Gender } \\
\hline \begin{tabular}{l|l} 
Male \\
\end{tabular} & 1 (Reference) & & 29.40 \\
\hline \begin{tabular}{l|l} 
& Female \\
\end{tabular} & $2.57(1.83,3.61)$ & $<.001$ & \\
\hline \multicolumn{4}{|c|}{ Objectively measured weight status $^{2}$} \\
\hline Overweight & 1 (Reference) & & 185.44 \\
\hline Obese & $0.03(0.02,0.06)$ & $<.001$ & \\
\hline \multicolumn{4}{|l|}{ Education } \\
\hline \begin{tabular}{l|l} 
& Primary only \\
\end{tabular} & 1 (Reference) & & 5.66 \\
\hline Secondary or diploma & $1.36(0.93,1.98)$ & .114 & \\
\hline \begin{tabular}{l|l} 
& Bachelor or higher \\
\end{tabular} & $2.03(1.11,3.70)$ & .021 & \\
\hline \multicolumn{4}{|l|}{ Self-rated health } \\
\hline \begin{tabular}{l|l} 
& Poor
\end{tabular} & 1 (Reference) & & 0.04 \\
\hline Good & $0.96(0.60,1.52)$ & 847 & \\
\hline \multicolumn{4}{|l|}{ Type 2 diabetes } \\
\hline \begin{tabular}{l|l} 
No \\
\end{tabular} & 1 (Reference) & & 0.62 \\
\hline Yes & $1.25(0.71,2.20)$ & .432 & \\
\hline \multicolumn{4}{|l|}{ Measured diet quality } \\
\hline \begin{tabular}{l|l} 
Poor \\
\end{tabular} & 1 (Reference) & & 0.08 \\
\hline Moderate & $0.95(0.65,1.38)$ & .774 & \\
\hline \begin{tabular}{l|l} 
Good \\
\end{tabular} & $0.96(0.63,1.47)$ & 860 & \\
\hline \multicolumn{4}{|c|}{ Told by health professional to lose weight } \\
\hline \begin{tabular}{l|l|} 
& No \\
\end{tabular} & 1 (Reference) & & 6.69 \\
\hline \begin{tabular}{l|l|} 
& Yes \\
\end{tabular} & $1.88(1.17,3.04)$ & 0.01 & \\
\hline \multicolumn{4}{|l|}{ On diet to lose weight } \\
\hline \begin{tabular}{l|l} 
& No \\
\end{tabular} & 1 (Reference) & & 36.24 \\
\hline Yes & $3.17(2.18,4.62)$ & $<.001$ & \\
\hline
\end{tabular}

Age is shown as a median (interquartile range). Numbers and \% (in brackets) for categorical variables will vary in different analyses as some variables have missing values.

${ }^{1}$ Odds ratios (OR) and 95\% confidence intervals (CI) for correct versus underestimation of BMI. All variables adjusted for each other. ${ }^{2}$ Overweight $=$ BMI: 25.0-29.9 kg/m² ; Obese $=$ BMI: $\geq 30 \mathrm{~kg} / \mathrm{m}^{2}$.

Significant P values (<.05) highlighted.

Table 4. Odds ratios ${ }^{1}$ for correct estimation of weight according to BMI levels among overweight and obese subjects.

\begin{tabular}{|c|c|c|c|c|c|c|c|c|c|c|}
\hline BMI & \multicolumn{2}{|c|}{ Model 1} & \multicolumn{2}{|c|}{ Model 2} & \multicolumn{2}{|c|}{ Model 3} & \multicolumn{2}{|c|}{ Model 4} & \multicolumn{2}{|c|}{ Model 5} \\
\hline & $\begin{array}{l}\text { OR }(95 \% \\
\text { CI) }\end{array}$ & $\begin{array}{c}\mathrm{P} \\
\text { trend }\end{array}$ & $\begin{array}{l}\text { OR }(95 \% \\
\text { CI })\end{array}$ & $\begin{array}{c}\mathrm{P} \\
\text { trend }\end{array}$ & $\begin{array}{c}\text { OR }(95 \% \\
\text { CI })\end{array}$ & $\mathrm{P}_{\text {trend }}$ & $\begin{array}{l}\text { OR }(95 \% \\
\text { CI) }\end{array}$ & $\begin{array}{c}\mathrm{P} \\
\text { trend }\end{array}$ & $\begin{array}{l}\text { OR }(95 \% \\
\text { CI) }\end{array}$ & $\mathrm{P}_{\text {trend }}$ \\
\hline $\begin{array}{l}\text { Q1 }{ }^{2}(25.00-26.17 \\
\mathrm{kg} / \mathrm{m}^{2} \text { or } 30.00-31.28 \\
\left.\mathrm{~kg} / \mathrm{m}^{2}\right)\end{array}$ & $\begin{array}{l}1 \\
\text { (Reference) }\end{array}$ & $<.001$ & $\begin{array}{l}1 \\
\text { (Reference) }\end{array}$ & $<.001$ & $\begin{array}{l}1 \\
\text { (Reference) }\end{array}$ & $<.001$ & $\begin{array}{l}1 \\
\text { (Reference) }\end{array}$ & $<.001$ & $\begin{array}{l}1 \\
\text { (Reference) }\end{array}$ & $<.001$ \\
\hline $\begin{array}{l}\mathrm{Q} 2{ }^{2}(26.18-27.42 \\
\mathrm{kg} / \mathrm{m}^{2} \text { or } 31.29-32.82 \\
\left.\mathrm{~kg} / \mathrm{m}^{2}\right)\end{array}$ & $\begin{array}{l}1.75 \\
2.53)\end{array}$ & & $\begin{array}{l}1.85 \\
2.70)\end{array}(1.26$ & & $\begin{array}{l}1.81 \\
2.70)\end{array}$ & & $\begin{array}{l}1.94 \\
2.90)\end{array}$ & & $\begin{array}{l}2.06 \\
3.32)\end{array}$ & \\
\hline $\begin{array}{l}\text { Q3 }{ }^{2}(27.43-28.49 \\
\mathrm{kg} / \mathrm{m}^{2} \text { or } 32.83-35.80 \\
\left.\mathrm{~kg} / \mathrm{m}^{2}\right)\end{array}$ & $\begin{array}{l}2.34 \\
3.38)\end{array}$ & & $\begin{array}{l}2.69 \\
3.92)\end{array}$ & & $\begin{array}{l}2.57 \\
3.82)\end{array}$ & & $\begin{array}{l}2.88 \text { (1.92, } \\
4.32)\end{array}$ & & $\begin{array}{l}3.57(2.19, \\
5.80)\end{array}$ & \\
\hline $\begin{array}{ll}\mathrm{Q} 4 & (28.50-29.99 \\
\mathrm{kg} / \mathrm{m}^{2} & \text { or } \quad \geq 35.81 \\
\left.\mathrm{~kg} / \mathrm{m}^{2}\right) & \end{array}$ & $\begin{array}{l}4.04(2.79, \\
5.84)\end{array}$ & & $\begin{array}{l}4.38(3.00, \\
6.39)\end{array}$ & & $\begin{array}{l}4.54 \\
6.76)\end{array}$ & & $\begin{array}{l}5.57 \\
8.48)\end{array}$ & & $\begin{array}{l}7.72(4.59, \\
12.98)\end{array}$ & \\
\hline
\end{tabular}

${ }^{1}$ Odds ratios (OR) and 95\% confidence intervals (CI) for correct versus underestimation of weight status. Q1 = lower BMI levels; Q4 = higher BMI levels.

Model 1: Unadjusted.

Model 2: Adjusted for gender.

Model 3: Adjusted for gender and education.

Model 4: Adjusted for gender, education, told by health professional to lose weight and on diet to lose weight.

Model 5: Adjusted for gender, education, told by health professional to lose weight, on diet to lose weight and objectively measured weight status: overweight/obese. 